Ciência e Natura, Santa Maria, v. 37 n. 4 set-dez. 2015, p.350-365

Revista do Centro de Ciências Naturais e Exatas - UFSM

ISSN impressa: 0100-8307 ISSN on-line: 2179-460X

\title{
ciênciaenatura
}

\section{Perfil do produtor rural no município de São João do Cariri e seus reflexos no processo produtivo: entre o tradicional e o moderno}

\author{
Profile of rural producers in São João do Cariri municipality, and its reflexes in the productive \\ process: between the traditional and the modern
}

\author{
Ronildo Alcântara Pereira, Clênia Rodrigues Alcântara
}

Universidade Federal de Campina Grande, UFCG

RESUMO

Existe hoje um forte apelo à prática da agricultura tradicional, devido ao seu caráter conservacionista - muito embora se deva ter cautela em relação aos termos tradicional e moderno quando se referem à agricultura, pois o moderno, se tomadas as devidas precauções, pode ser sustentável; e o tradicional, se optar pelos insumos modernos, torna-se tão impactante quando o primeiro. Esta é a realidade encontrada ao se levantar os perfis, tanto do produtor quanto da agricultura, no município de São João do Cariri, cujo sistema de produção, ao mesmo tempo em que é praticado nos moldes mais tradicionais da agricultura, se utiliza de insumos modernos (produtos químicos), pondo em risco não somente a integridade física das pessoas, mas também contaminando o meio ambiente. Este sistema produtivo reflete as condições precárias dos agricultores, em que lhes faltam acesso às novas técnicas agrícolas e assistência técnica para alcançar boa produtividade e, por conseguinte, melhores condições de vida. Frente a essas questões, este estudo tem como finalidade analisar alguns indicadores de deterioração das práticas utilizadas na agricultura de subsistência no município e levantar o perfil socioeconômico dos produtores locais, através de suas práticas. Os resultados apontam para um comprometimento de metade da capacidade de produção, devido às técnicas adotadas.

Palavras-chave: Sistemas agrícolas, externalidades ambientais, produtor rural.

\section{ABSTRACT}

There is nowadays a strong appeal to the traditional agricultural practices, due to their conservationist character although it should take caution when it comes to "traditional" and "modern" terms as they relate to agriculture, because the modern, if taken with proper precautions can be sustainable; and the traditional, opting for modern inputs, becomes as impactful as the first. This is the reality found upon profiles rising from both the producer and agriculture in the municipality of São João do Cariri, where while the production system practiced in more traditional forms of agriculture, also makes use of modern inputs (chemical products), endangering not only the physical integrity of people, but also contaminating the environment. This productive system reflects the precarious conditions of farmers in that they lack access to new agricultural techniques and technical assistance to achieve high productivity and therefore better living conditions. Giving these issues, this study aims to analyze some indicators of deteriorating practices in subsistence agriculture in the county and raise the economic profile of local producers, through their practices. The results point to a commitment of half the production capacity, due to the adopted techniques.

Keywords: Farming Systems, Environmental Externalities, Agricultural Producer. 


\section{INTRODUÇÃO}

Preocupações sobre a capacidade da agricultura para prover de forma sustentável as necessidades das populações humanas não são novas e por vezes se repetem. A teoria malthusiana, por exemplo, tinha como foco o argumento de que, por causa da lei da produtividade marginal decrescente, a agricultura seria limitada em sua capacidade para alimentar uma população em crescimento. Mais tarde, David Ricardo, economista inglês do século XIX, argumentaria que com investimento de capital técnico ou científico e progresso suficiente na agricultura, o problema malthusiano não se confirmaria. Ele foi apoiado pela visão capitalista, de acordo com a qual é possível afirmar que nada é impossível para a ciência (TISDELL, 2007).

Todavia, existem dúvidas se as práticas modernas que potencializam a produção permitiriam por muito tempo a sustentabilidade dos sistemas agrícolas modernos, devido aos impactos negativos sobre o meio circundante. Alega-se que a aplicação de métodos modernos e insumos na agricultura com o intuito de crescimento, traz mudanças sobre o meio ambiente que depreciarão o crescimento, pressionando o nível de produção agrícola e, por conseguinte, comprometendo a oferta de alimentos (ALTIERI, 2004).

Assim sendo, deve-se ter em mente que a sustentabilidade da produção agrícola é um valioso atributo do desempenho dos sistemas e que, a partir desse aspecto, os conceitos de sistema moderno e tradicional se tornam genéricos. Basta observar que, embora a agricultura itinerante possa ser relativamente sustentável, quando os ciclos de rotação são suficientemente reduzidos, os rendimentos declinam e ela deixa de ser sustentável. Da mesma forma ocorre com sistemas modernos, os quais, caso seja aplicada a devida cautela, podem ser tão sustentáveis quanto o método tradicional, embora sejam raras as ocorrências neste sentido (TISDELL, op. cit.).

Os sistemas agrícolas tradicionais são, a priori, caracterizados por vários recursos que ajudam a manter os rendimentos. Estes incluem o uso de variedades locais de culturas, manutenção de ciclos fechados de materiais e poucos resíduos em virtude de práticas eficazes de reciclagem, controle biológico de pragas, entre outros (ALTIERI, op. cit.).

Contudo, não é raro os sistemas tradicionais aderirem aos insumos da agricultura moderna, tornando-se fonte de externalidades ambientais desfavoráveis ou situações extremas. Isso em muito se deve aos apelos da mídia, dos fabricantes e, principalmente, do agronegócio, visando maior produtividade e lucro. Seduzidas por tal convite, muitas organizações familiares optam por trabalhar com produtos químicos, sem, no entanto, dispor de estrutura mínima e conhecimento prévio para manuseá-los, o que põe em risco a saúde dos agricultores e consumidores, bem como a qualidade dos produtos.

De acordo com Faria et al. (2004), o uso de agrotóxicos na agricultura é intensivo, multiquímico e várias publicações têm apontado as intoxicações como um grave problema de saúde, especialmente entre trabalhadores rurais. Entretanto, são raros os estudos brasileiros de base populacional sobre as características do uso ocupacional ou sobre contaminação.

$\mathrm{Na}$ área de estudo em análise, o município de São João do Cariri - PB, onde o sistema produtivo é praticado, em sua grande maioria, em pequenas propriedades nunca superiores a cem hectares e as relações de trabalho se dão entre membros da mesma família, portanto caracterizando-se como agricultura familiar (INCRA, 2000), a utilização de agrotóxico é uma prática comum e se constitui num fator capital para a manutenção da sustentabilidade das organizações agrícolas locais. E esse não é o único aspecto com 
repercussão negativa a se refletir no ambiente e na qualidade de vida da comunidade. Também podem ser destacados o grau de organização dos produtores, o nível tecnológico dos equipamentos utilizados na produção, os aspectos econômicos (venda da produção, preço etc.) e a falta de assistência técnica, entre outras limitações.

A pesar de todos os problemas enfrentados pela agricultura no município de São João do Cariri, no que se refere ao meio físico, o índice de deterioração deste foi o que apresentou o mais baixo valor, em comparação aos demais aludidos. Entretanto, tal índice ainda estava fora do limite aceitável, segundo a metodologia utilizada.

Ante as questões levantadas, este estudo tem como proposta analisar alguns indicadores de deterioração das práticas utilizadas na agricultura familiar do município de São João do Cariri - PB e levantar o perfil socioeconômico dos produtores locais, através das práticas do sistema produtivo, em suas diversas variáveis. Assim, tenta-se entender quais práticas estão sendo utilizadas e que relação existe entre estas práticas e o perfil do produtor nos diversos aspectos analisados.

\section{MATERIAL E MÉTODO}

Como forma de atender aos objetivos propostos, este estudo foi elaborado a partir de referencial teórico referente ao assunto e à área de estudo, bem como a mapas regionais que abordam as questões. Utilizaram-se técnicas de fotointerpretação, através de imagens de satélite por sensoriamento remoto, como forma de identificar as áreas de maior grau de antropização. Por fim, empreendeu-se um trabalho de campo, através do qual foi viabilizado o conhecimento da área, bem como a aplicação de um questionário, para provimento das informações sobre as práticas produtivas realizadas e demais informações que esclareçam aspectos da cadeia produtiva do sistema local.

O aspecto que mais influenciou a escolha da área para aplicação dos questionários tomou por base a densidade populacional existente nas propriedades contíguas ao rio Taperoá. Essa maior quantidade de comunidades foi identificada através do mapa diagnóstico realizado pelo IBGE (2000), o qual aponta que, dentre os cinco setores rurais cadastrados no município, pelo menos três encontram-se na área em análise, fato confirmado pelo processo de fotointerpretação das imagens da área, as quais mostraram um elevado grau de antropismo. Esta área contrasta frontalmente com as demais áreas da zona rural do município, que são compostas, principalmente, por grandes propriedades (com mais de 300 hectares) e se destina a pecuária extensiva.

Estes aglomerados rurais formados por estabelecimento nunca maiores que 100 hectares concentram aproximadamente 900 habitantes, representando cerca de $60 \%$ de todo contingente populacional da zona rural do município. Além disso, outro aspecto justifica tal escolha, já que, diferentemente de outras áreas, ali a estrutura fundiária sofreu uma grande transformação na fragmentação das propriedades (devido ao processo de hereditariedade), resultando na alta densidade demográfica, motivada, principalmente, pela proximidade da oferta de água.

O método utilizado na aplicação dos questionários, que estimou o nível de deterioração socioeconômica e ambiental, deriva do Centro Interamericano de Desenvolvimento de Águas e Terras (CIDIAT) da Venezuela e que foi adaptado por Rocha (1997) para as condições brasileiras. Esse método fornece um panorama tanto da ambiência quanto do meio antrópico da área sugerida para o estudo. Quanto à validação do método, outros autores já fizeram uso da aplicação desse modo de investigação no Semiárido 
Paraibano. Entre estes se podem destacar: Baracuhy (2001), Franco (2002), Azevedo et. al. (2005), Pereira (2008) e Melo et al. (2010).

Para se determinar os percentuais de deterioração (y), utilizou-se a equação da reta:

$$
\mathrm{y}=a x+b
$$

Em que y é a unidade de deterioração e varia de 0 a 100; x é o valor modal encontrado a partir da tabela de códigos; $x^{\prime}$ e $x^{\prime \prime}$ são os valores mínimos e máximos, respectivamente; a e b são os coeficientes da equação da reta.

\section{1 Área de estudo}

O município de São João do Cariri (Figura 01) faz parte da região compreendida pelo Polígono das Secas e está localizado na parte central do Estado da Paraíba. Possui uma área de $702 \mathrm{Km}^{2}$ e uma população de 4.334 habitantes, dos quais $46 \%$ residem na zona rural (IBGE, op. cit.).

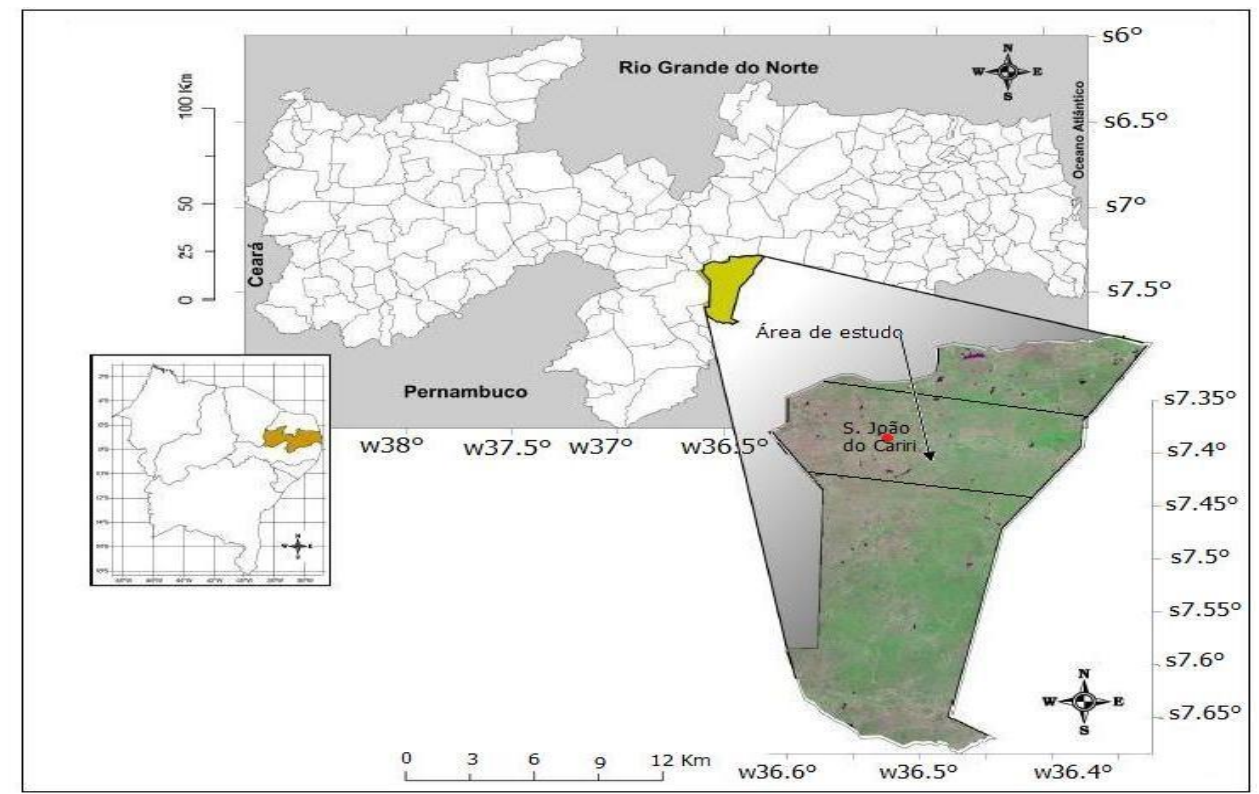

Figura 1: Localização de São João do Cariri no contexto do Nordeste brasileiro, do estado da Paraíba e área de maior antropização, que serviu à aplicação dos questionários.

O clima é quente e úmido, classificado por Köppen como Bsh, e caracterizado por uma baixa e irregular pluviosidade concentrada em apenas três meses do ano (Figura 2), na faixa compreendida entre 300 e $900 \mathrm{~mm} /$ ano. As temperaturas médias anuais são da ordem de 26 a $30^{\circ} \mathrm{C}$ (DANNI-OLIVEIRA; MENDONÇA, 2007). 


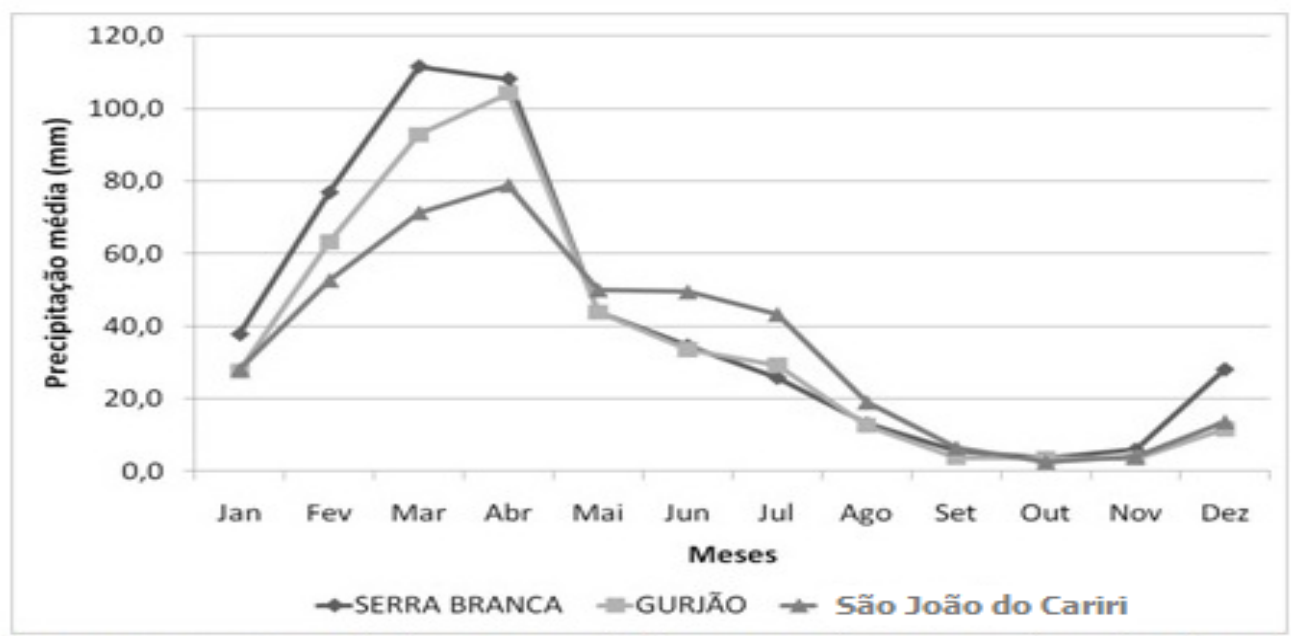

Figura 2: Valores médios mensais da precipitação e distribuição temporal das chuvas entre 1965 e 2011, no município e áreas limítrofes. Fonte: Paraíba (2011).

A estrutura geológica do município é constituída do embasamento cristalino do Pré-cambriano indiviso. Sobre esse aspecto, Dantas e Caúla (1982) afirmam que: “trata-se de um substrato impermeável, que não dispõe de aquífero generalizado, excetuando-se os casos de depósitos confinados em falhamentos". Esse aspecto se reveste de uma notável relevância, de vez que se traduz em um fator limitador para a oferta de água subterrânea numa área por demais carente deste recurso.

A área é recoberta por vegetação da Caatinga, segundo Andrade-Lima e Silva (1982), variando de arbustiva esparsa a arbustiva muito rala. Para Alves (2007), a cobertura vegetal dessa área é representada por formações caducifólias, muito diversificadas por razões climáticas, edáficas, topográficas e antrópicas (Figura 3).
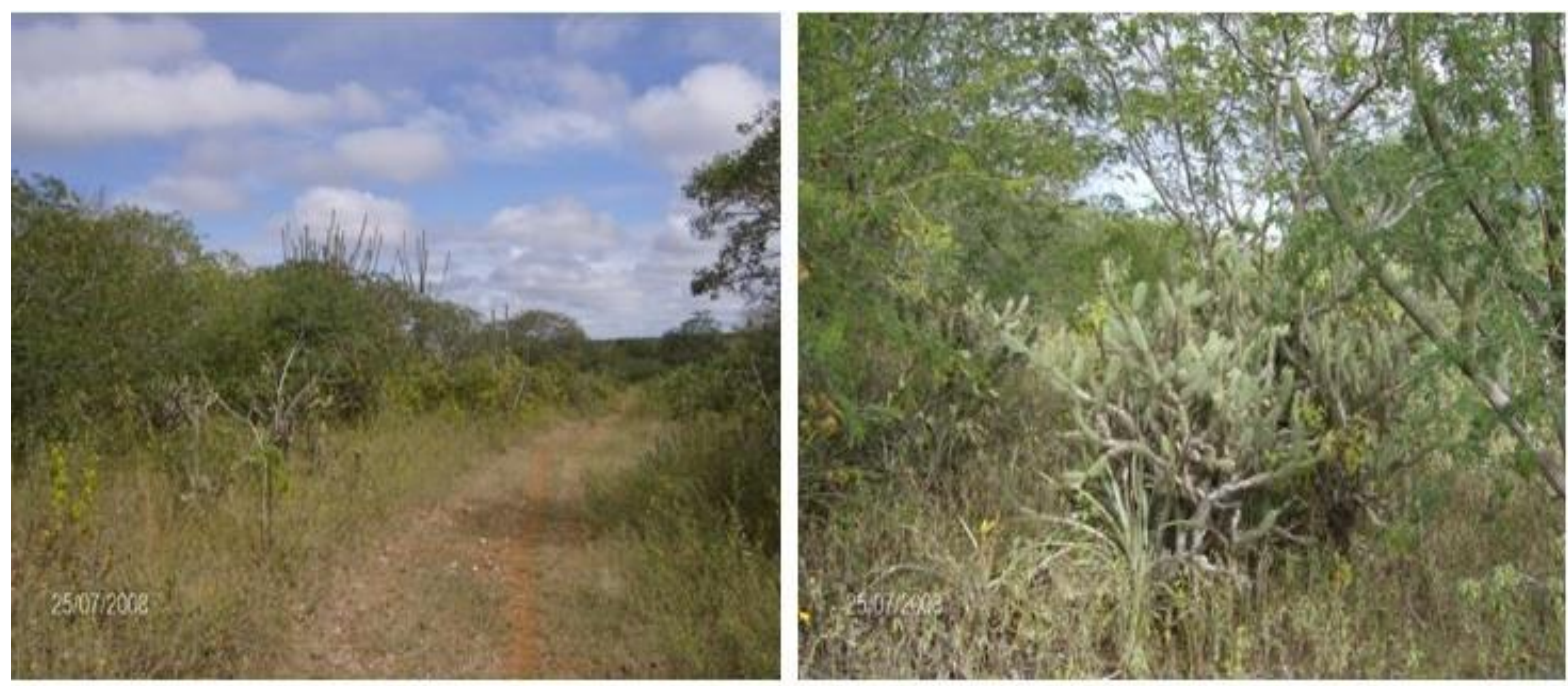

Figura 3: Fotos de campo da vegetação típica encontrada na área de estudo. 


\section{RESULTADOS E DISCUSSÃO}

Após o processamento das imagens, a etapa seguinte da pesquisa constituiu-se da aplicação do questionário, que contemplou as seis varáveis indicadoras dos níveis de deterioração do sistema produtivo, composto pelo fator social, através dos seguintes aspectos: demográfico, organizacional, habitacional, de salubridade, alimentar e de cumprimento das leis, o que possibilitou a elaboração das retas com os níveis encontrados.

Os dados levantados entre as variáveis deste segmento requerem algumas considerações, em função da relevância que assumem, frente ao contexto da área pesquisada. Dentre estes aspectos pode-se destacar a idade do chefe da família maior de 66 anos, que apresentou uma frequência 29 de ocorrência, além de outros dados não menos relevantes que podem ser observados na Tabela 1.

Tabela 1: Frequências de maior relevância para a estabilidade social no âmbito do núcleo familiar da área de estudo

\begin{tabular}{|c|c|c|}
\hline Fator social/item pesquisado & Maior frequência & \% do total \\
\hline Idade do chefe de família & Acima de 66 anos (29) & 25 \\
\hline Grau de instrução do chefe de família & Ensino fundamental (57) & 48 \\
\hline Local de nascimento do chefe de família & Nascidos na zona rural (76) & 64 \\
\hline Residência do chefe de família & Mora na propriedade (71) & 60 \\
\hline Número de famílias na propriedade & Uma família (50) & 42 \\
\hline Média de idade do núcleo familiar & Entre 41 e 50 anos (53) & 45 \\
\hline
\end{tabular}

O percentual de $25 \%$ dos chefes de família com idade superior a 66 anos aponta para uma perspectiva sóbria com relação à continuidade da permanência das famílias na zona rural, uma vez que, morrendo o gestor do núcleo, desencadeia-se, a priori, uma desorganização social e econômica das pessoas pertencentes ao clã. Esse fato, de alguma maneira, já vem ocorrendo, devido à falta de assistência ao homem do campo, fato incentivado também pelo apelo da mídia, que mostra as vantagens da vida urbana. Assim, qualquer aspecto desestruturante contribui para intensificar o êxodo rural.

O grau de instrução é outro aspecto relevante no perfil desses produtores, pois esse fator, consorciado com o local de nascimento, concorre para aumentar o nível de dificuldade desta organização familiar, haja vista a ausência histórica de boas escolas na zona rural, sobretudo no Nordeste Brasileiro. Já a naturalidade dos produtores, quando nascidos na própria localidade, contribui negativamente para uma visão sinótica da realidade, dificultando em grande medida o conhecimento do meio físico, dos processos produtivos, das técnicas de manejo, entre outros aspectos (BARACUHY, op. cit.). Dessa realidade vivida pelo homem do campo decorre outra faceta não menos importante, que é a falta de perspectiva dos jovens da zona rural, restando-lhes como alternativa a migração para centros maiores, visando melhores condições de vida.

No item que registra o número de famílias morando na propriedade, a priori, o fato não representa problemas, a não ser quando a prole é numerosa, fato este que torna difícil produzir, morar e até mesmo conviver. Já a idade média nos diversos núcleos familiares 
pesquisados revela um dado preocupante, pois mostra uma quantidade significativa de pessoas que têm entre 50 e 60 anos. Em outras palavras, em uma década a área terá uma parcela significativa de idosos, reforçando a ideia de solução por continuidade.

Sobre os hábitos alimentares da população, os dados da Tabela 2 deixam claro que a dieta posta em prática por este contingente rural se mostra deficitária em alguns grupos de alimentos, enquanto em outros, perfeitamente dispensáveis, há consumo muito maior que o necessário. Os alimentos de origem animal (derivados do leite, por exemplo), mostra um consumo muito alto, enquanto que frutas e legumes apresentam valores extremamente baixos.

Tabela 2: Frequências no âmbito do consumo alimentar das famílias da área de estudo.

\begin{tabular}{|c|c|c|}
\hline Fator social/ itens pesquisados & Consumo & \% do total \\
\hline Consumo de carne (gado, porco ou caça) & Alto (33) & 28,5 \\
\hline Consumo de frutas & Médio (16) & 13,5 \\
\hline Consumo de legumes/verduras & Baixo (07) & 0,6 \\
\hline Consumo de ovos & Médio (18) & 15,0 \\
\hline Consumo de massas (macarrão) & Baixo (13) & 11,0 \\
\hline Consumo de arroz e/ou feijão & Alto (35) & 25,0 \\
\hline Consumo de peixes & Médio (16) & 13,5 \\
\hline
\end{tabular}

Frente ao contexto hora exposto, a unidade de deterioração socioeconômica, representada graficamente na Figura 4, externa os problemas encontrados na área, os quais carecem de reflexão, pois apresenta percentuais de deterioração bastante aumentados.

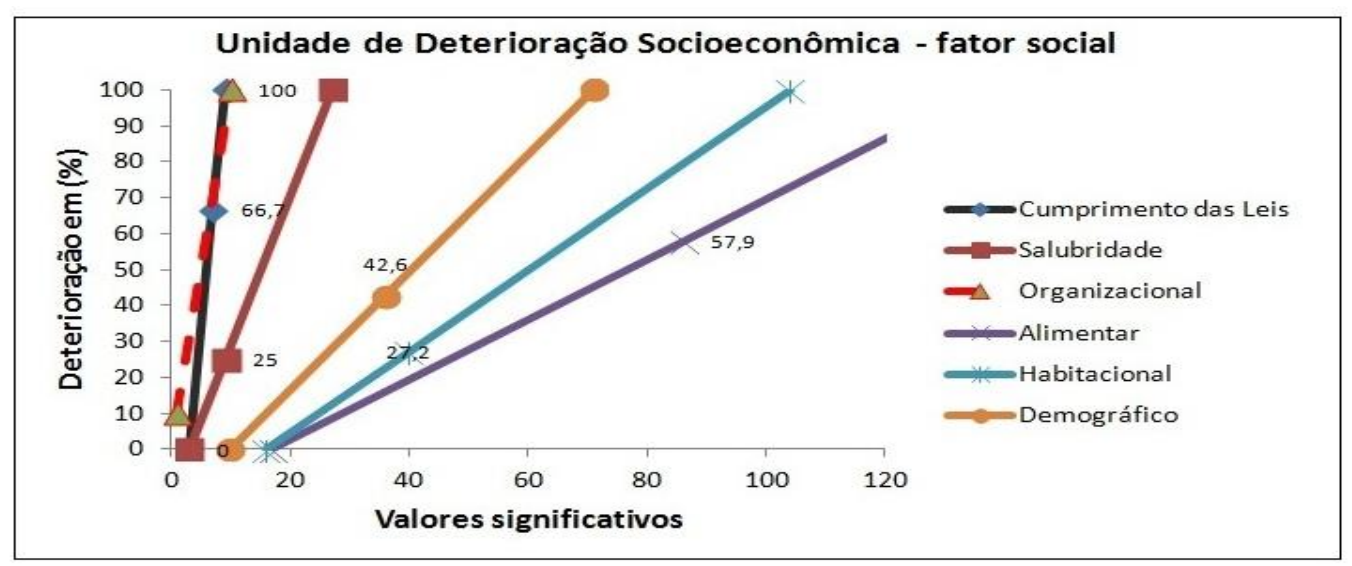

Figura 4: Retas das variáveis para unidade crítica de deterioração socioeconômica e os fatores sociais.

Observa-se, através dos dados contidos no gráfico da Figura 4, obtidos para a variável demográfica, que o valor de 42,6\% apurado ficou levemente abaixo dos 45\% verificados por Azevedo et al. (op. cit.) na bacia hidráulica do Açude Epitácio Pessoa, e acima dos 39,8\% levantados por Baracuhy (op. cit.) para a microbacia do Riacho PausBrancos no município de Campina Grande. A comparação entre tais estudos se faz necessária, haja vista se tratarem de áreas com características análogas, fornecendo assim um parâmetro robusto. Desse valor, depreende-se também que existe uma má distribuição das terras para o processo produtivo e que há, sem dúvida, uma considerável concentração 
de pessoas vivendo em minifúndios, o que pode torná-los insuficientes para oferecer uma produção que atenda às suas necessidades.

Ainda de acordo com a Figura 4, no que refere à variável habitação, como se pode observar, esta apresentou o valor de deterioração bastante diverso $(27,2 \%)$ dos demais índices, inclusive dos encontrados por Azevedo et al. (op. cit.), cujos valores determinados se aproximaram do valor máximo (100\%).

A explicação para um valor tão baixo deve-se à boa qualidade das moradias que, em sua grande maioria, derivam de herança de um tempo em que a área era explorada por fazendas de gado. Contudo, este índice poderia ser ainda menor se não fossem os problemas relacionados à falta de estrutura para a correta destinação de esgotos, eliminação de lixo e de embalagens de agrotóxicos.

A variável alimentar apresentou um índice de deterioração de $58 \%$, em virtude principalmente da falta de orientação nutricional nas comunidades. Ali se prioriza enormemente as gorduras e sacarose, em detrimento das frutas, hortaliças e tubérculos. Mesmo assim, devido ao tipo de atividades cotidianas dessas pessoas, que as deixam longe do sedentarismo, não se observou maiores problemas em relação à obesidade. Outro aspecto que ficou patente, e que sem dúvida reforça a assertiva acima, é o elevado número de pessoas acima dos sessenta anos.

No que diz respeito à participação em organizações de classe, registrou-se o valor máximo de deterioração (100\%), fato que se deve, segundo o que se pôde apurar, à falta de credibilidade das instituições em questão, bem como à ausência de esclarecimento da importância e dos benefícios trazidos por associações fortes e atuantes, sobretudo na defesa dos associados mais participativos. Parece claro que a baixa escolaridade também contribui significativamente para a manutenção deste quadro.

A variável salubridade humana registrou um índice relativamente baixo de $25 \%$ para os padrões da área, os quais decorrem das boas condições das habitações, o que se traduz na constituição de um ambiente salutar. Para alcançar tal índice, as instalações bem ventiladas e com pé direto adequado foram seguramente determinantes, não obstante a falta de saneamento básico.

Outra questão de suma importância, e que está diretamente relacionada à salubridade, trata da água consumida. Neste quesito, $60 \%$ dos contatados afirmaram que a água consumida é potável. Todavia, quando questionados acerca da origem desta água, as respostas convergem para o mesmo ponto: ou vêm de bicas e cisternas ou de cacimbas, barreiros e outras formas de acumulação. Sobre este assunto, Diniz (1995) afirma que o problema relativo à qualidade da água consumida nas propriedades rurais do semiárido está muito mais associado ao manuseio do que à forma de acumulação. Assim, a potabilidade está muito mais ligada a assepsia, e esse aspecto é muito pouco observado.

Finalmente, na variável observância das leis trabalhistas, registrou-se o valor de $66 \%$, devido principalmente à prática da informalidade. Entretanto, um aspecto positivo foi constatação da ausência de trabalho infantil. No caso da falta de registro em carteira, essa realidade decorre principalmente de alguns fatores: da falta de esclarecimento dos trabalhadores, da falta de condições econômicas de muitos produtores e dos altos encargos sociais que tornam inviável o registro adequado.

O aspecto referido é extremamente danoso à condição social do trabalhador, considerando-se os prejuízos relativos à questão previdenciária. Dessa forma, o empregado informal que futuramente procurar belo benefício da aposentadoria será surpreendido pela falta de contribuição à previdência social, condição indispensável à sua concessão. 
Os resultados relativos à unidade crítica de deterioração econômica (Figura 5) mostram valores elevados nas diversas variáveis estudadas, atestando que o elemento determinante, no que diz respeito à produção rural, reside justamente na venda do produto do trabalho, nem sempre ao comprador ideal ou a preço justo. Dessa forma, mais da metade daqueles que produzem em seus sítios comercializa sua produção junto a atravessadores, nunca pelo valor de mercado, mas pelo que estes se dispõem a pagar. Com isso, muitos veem o esforço de meses de labuta ser trocado por quantias irrisórias, deixando, por outro lado, ao comerciante altos lucros sem o mesmo ter despendido o menor esforço para obtêlos.

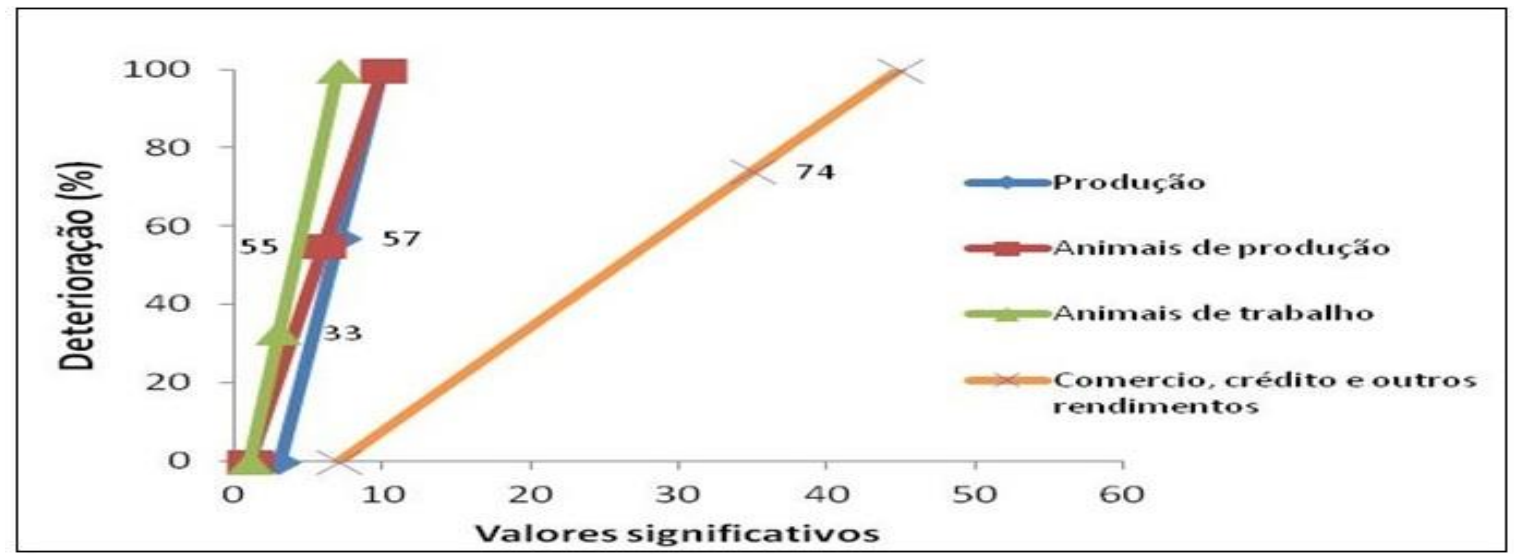

Figura 5: Retas das variáveis para unidade crítica de deterioração socioeconômica e os fatores econômicos.

Com esta forma precária de comércio, a questão se reflete no índice de 57,8\% de deterioração para a variável produção, evidenciando o que já fora mencionado, em que a falta de organização em cooperativas ou outra representação que zele pelos interesses da classe faz bastante falta. Esse dado revela também a ausência de outro aspecto deveras importante para o êxito da produção agrícola e sua da viabilidade econômica, que é o comprador. Agindo por conta e risco, fica muito mais complexo para o produtor usufruir dos benefícios da produção e suas vantagens relacionadas.

No que diz respeito à posse de animais para o trabalho, o valor de $33,3 \%$ retrata a dificuldade financeira enfrentada por muitos dos pequenos produtores quanto ao modo como produzem na terra, pois dispõem apenas das suas próprias forças para trabalhar. Isso mostra que o modo de produção ali ainda se faz de forma arcaica, com reflexo na produtividade e no lucro.

Outro aspecto relacionado a essa questão tem a ver com as mudanças tecnológicas ocorridas durante as últimas duas décadas, período em que o homem do campo veio substituindo o meio de transporte, antes realizados através de animais (burro e cavalo), os quais podiam ser aproveitados também como tração no trato da terra, pela motocicleta, pouco útil à tarefa de arar, transportar etc. Todavia, a despeito deste suposto avanço, no que concerne à produção, os instrumentos utilizados ainda são os mesmos de séculos passados.

Ainda sobre a Figura 5, no que se refere à variável criação de animais de produção, o valor encontrado (55\%) evidencia a ausência de uma produção mais intensiva neste setor. O fato tem explicação na instabilidade climática existente na área de estudo, onde muitas vezes se perde parcela significativa dos rebanhos por falta de condições de mantê-los 
alimentados e dessedentados. Contudo, é difícil encontrar qualquer núcleo familiar que não disponha de criação de galinhas, porcos e vacas ou cabras para o consumo interno. Esse tipo de recurso, no qual se despreza o excedente, representa para muitos a liquidez imediata para levantar valores emergenciais, ou seja, é uma forma de poupança perante as necessidades.

A variável comercialização, aquela de mais alto percentual deste segmento $(74,0 \%)$, traduz a dificuldade de vender o que é produzido na propriedade. Por trás deste índice também se encontram outras questões que o produtor rural não consegue superar: a baixa produtividade, decorrente de práticas obsoletas; a falta de crédito, a falta de insumos, a inexistência de assistência técnica e de aparato tecnológico eficiente, moderno e acessível.

Existem, ainda, outros aspectos que inibem a produção e que se refletem na comercialização, contribuindo para a deterioração da atividade rural. Entre esses se podem citar as políticas públicas assistenciais (leia-se as bolsas) que, se por um lado, diminuem a pressão sobre os recursos naturais - da vegetação (evitando a derrubada desta para a fabricação de carvão), por exemplo -, de outro, dificultam sensivelmente a oferta de mão de obra, fazendo com que muitos proprietários abandonem suas propriedades na zona rural, haja vista a falta de trabalhadores para realizar as tarefas diárias.

Conforme o Ministério do Desenvolvimento Social (MDS, 2014), o programa bolsa família tem cadastrado, em média, setecentas famílias no município em exame, fato que contabiliza aproximadamente sessenta por cento da população, considerando-se quatro indivíduos por núcleo familiar e uma incidência de pobreza da ordem de cinquenta e três por cento (IBGE, 2010).

Segundo o órgão supracitado, os benefícios pagos às famílias, em números atualizados (agosto de 2014) foram da ordem de $\mathrm{R} \$ 200,00$ por família. Além disso, conforme este estudo, o fato de vinte e cinco por cento da população rural ser beneficiaria da previdência social, via sindicato rural, em muito reforça a renda familiar.

A constatação da influência dos benefícios fica mais evidente, ao se observar o depoimento de produtores contatados por este estudo. Conforme suas falas, numa grande parcela dos núcleos familiares, os idosos aposentados são responsáveis por boa parte da renda que os sustentam. Além disso, na última década, as "Bolsas" do Governo Federal destinadas a manter as crianças na escola, bem como o "seguro-safra", responderam por outra parte das despesas das famílias. Com isso, muitos adultos em condições de vender a força de trabalho não o fazem, apesar de os valores dos benefícios recebidos serem considerados baixos e da ausência de outras fontes de renda que caracterizem a pluriatividade (SCHNEIDER, 2003).

No tocante aos produtos de origem vegetal, como lenha, estacas e carvão, sua comercialização ao longo desta década sofreu um decréscimo considerável em razão do significativo apoio financeiro dos programas sociais acima referenciados. Em vista destas questões, essa unidade de deterioração apresentou resultados tão elevados $(54,7 \%)$, em parte, ajudados pela falta de produtividade, comercialização e linhas de crédito e outros rendimentos.

Os valores relativos às questões da unidade crítica de deterioração socioeconômica e os fatores tecnológicos se mostraram excessivamente altos (Figura 6), decorrentes de alguns fatores bem característicos da área de estudo. Um deles diz respeito à descapitalização dos pequenos proprietários que, devido à pouca disponibilidade de terras para produzirem (até mesmo para oferecer como garantia hipotecária), contam com o crédito oficial proporcional ao que possuem. 
Dessa forma, as tecnologias utilizadas para produzir na área encontram-se muito aquém daquelas empregadas na moderna agricultura. Os equipamentos ainda hoje se resumem a enxadas, foices e machados e outros, que exigem muito da força física do produtor. Para Rebouças (1997), os equipamentos utilizados na agricultura do Semiárido na atualidade e em muitos locais se diferenciam daquelas da revolução Neolítica apenas por serem de metal.

De acordo com a frequência das respostas, tratores, motor-serra e outros utensílios modernos são para poucos. Esse atraso tem reflexo direto na produtividade, e reduz a oferta de produtos, até mesmo aqueles de primeira necessidade, como mostrado anteriormente.

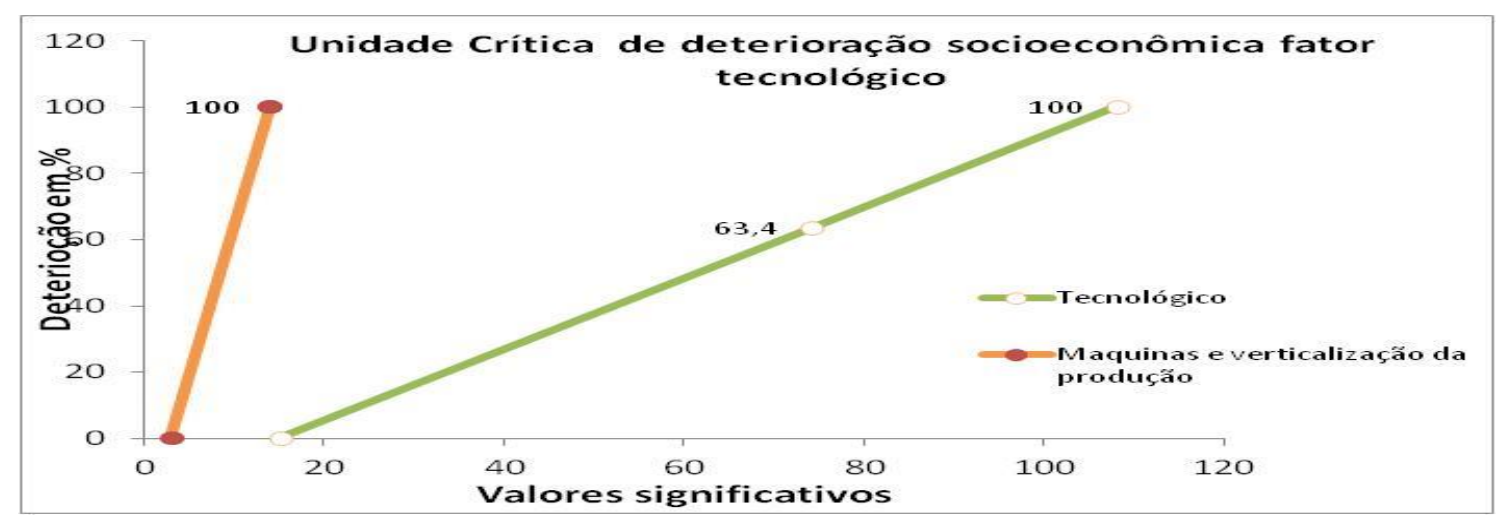

Figura 6: Retas das variáveis para unidade crítica de deterioração socioeconômica e os fatores tecnológicos.

Outro fator que se pode destacar, e que colabora enormemente para entravar a produção, é a estrutura agrária que concentra grandes propriedades nas mãos de poucos, ao passo que os que têm pouca terra ainda necessitam dividir com seus familiares, por diversas razões, entre elas a herança. Dessa partilha, resulta um contingente considerável de pessoas vivendo em minúsculos minifúndios, sem que os mesmos possam atender às necessidades de todos. Daí o fato de surgirem problemas de diversas ordens, dentre os quais se destaca o êxodo para as cidades. Dessa forma, descapitalizado e sem assistência técnica e informacional, fica inacessível ao pequeno produtor familiar modernizar seus meios de produção e, com isso, lograr melhores resultados.

Sobre a problemática em questão, o que mais preocupa é que, numa projeção para o futuro próximo, não há nenhum indicativo de que este cenário se altere, uma vez que, com o produtor descapitalizado, sem instrução e perdendo os membros jovens da família para os atrativos oferecidos pela vida nas cidades, mudanças são cada vez menos prováveis.

De acordo com a Figura 6, no item que aborda a questão da verticalização da produção rural, o valor de $100 \%$ encontrado é o reflexo do tipo de tratamento que as Instituições Públicas destinam ao desenvolvimento da pequena agricultura familiar nos municípios do semiárido brasileiro.

De acordo com as informações levantadas, dos cento e trinta (130) proprietários que responderam ao questionário, cerca de $90 \%$ deles gostariam de contar com orientação técnica e noções de conservação e preservação dos recursos que exploram. No entanto, o percentual encontrado assegura que essa condição inexiste para os pequenos produtores desta área. 
$\mathrm{Na}$ visita realizada aos produtores, observou-se que, apesar de alguns deles utilizarem algumas técnicas de uso eficiente de água na irrigação (gotejamento, por exemplo), outros procedimentos, como o manuseio dos agrotóxicos de forma incorreta, põem em risco a sustentabilidade do meio ambiente e a saúde humana ao comprometerem a qualidade dos solos e da água, principalmente.

Os dados relativos ao diagnóstico ambiental foram obtidos através do levantamento dos elementos que poluem diretamente o meio ambiente. Esse tipo de levantamento reflete sem disfarces a convergência dos demais fatores anteriormente analisados.

Nesse contexto, a radiografia das condições do meio físico, em que pese apresentar o menor dos índices aqui apurados, se encontra em um patamar muito além dos indicadores preconizados por muitos estudos e entidades, recomendados para o equilíbrio entre a exploração e a conservação dos recursos disponíveis.

Dentre os trinta itens aqui pesquisados, ao menos cinco deles, agrupados em dois segmentos, chamam a atenção, tanto pela frequência com que se registram quanto pela gravidade que representam. Trata-se de: (i) aplicação de agrotóxico sem controle, reaproveitamento e lavagem de embalagens de defensivos e aplicação de inseticida em culturas e safra; (ii) descarte de resíduo sólido, urbano e rural, livres e esgoto a céu aberto.

Os aspectos a serem destacados no primeiro grupo referem-se ao espectro dos efeitos, os quais perpassam a área onde a ação ocorre. Isso porque as substâncias alcançam o lençol freático e águas subterrâneas e passam a contaminar as áreas a jusante até o nível de base regional. No que se refere à contaminação biológica, os efeitos desses agentes tóxicos não apenas comprometem a saúde humana, mas podem ocasionar a perda da microfauna em ambientes lênticos e lóticos, afetando toda a cadeia alimentar.

No segundo grupo de ações poluentes, percebe-se o desconhecimento dos produtores rurais no que diz respeito ao descarte de resíduos sólidos e dejetos. Parte-se do princípio de que o desconhecimento dos problemas que podem advir pelo contato com tais substâncias encontram eco na falta de esclarecimento, na baixa escolaridade e na indisponibilidade de recursos financeiros para a construção de infraestrutura adequada à deposição adequada destes resíduos, de suma importância para a salubridade do meio vivido.

Faz-se pertinente lembrar que o quadro degradante acima relatado não ocorre apenas no meio rural. Nas cidades localizadas no âmbito da bacia do Rio Paraíba e, particularmente, no município foco deste estudo, todo o esgoto gerado pelas residências são lançados no Rio Taperoá. Assim, o rio que deveria servir de fonte de água à produção, se presta ao transporte de dejetos, contribuindo para degradação do meio circundante (TUDISI; TUNDISI, 2008).

O diagnóstico com a reta de deterioração está apresentado na Figura 7, cujo valor de deterioração se mostrou em $19 \%$, a despeito de todos os fatores que contribuem para o atual estágio da degradação ambiental no município. Os dados revelam que a deterioração está bem abaixo se comprada aos demais índices aqui estudados, muito embora demasiadamente alto se comparado ao que recomenda a metodologia de Rocha (op. cit.) aqui aplicada $(10 \%)$ e tida como satisfatório para um ambiente equilibrado. 


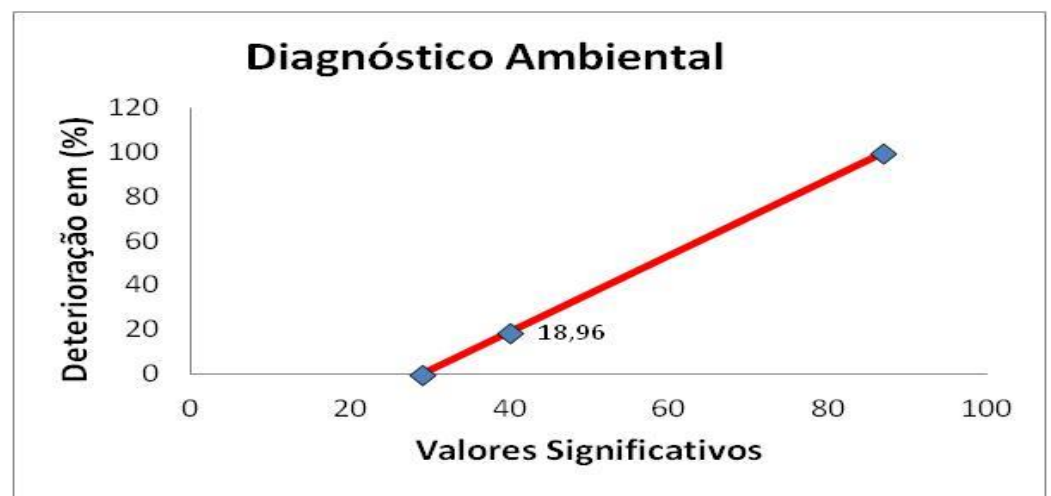

Figura 7: Reta para unidade crítica de deterioração ambiental na área de estudo.

A explicação para o resultado mostrado na Figura 6 pode advir da ausência de indústrias, garimpos ou queimadas na área em apreço. Porém outros aspectos foram determinantes para que se chegasse a esse valor. Além das ações anteriormente elencadas, outras formas de poluir podem ser agregadas a este processo, entre as quais se pode citar: exploração extensiva das propriedades, pocilgas, queimadas, entre outros. Entretanto o fato mais relevante que cabe uma reflexão é, sem dúvidas a aplicação de defensivos e, principalmente, a destinação das embalagens descartadas livremente no meio ambiente (Figura 8), fazendo crer que esta é uma ação que traz consequências danosas em diversas escalas.

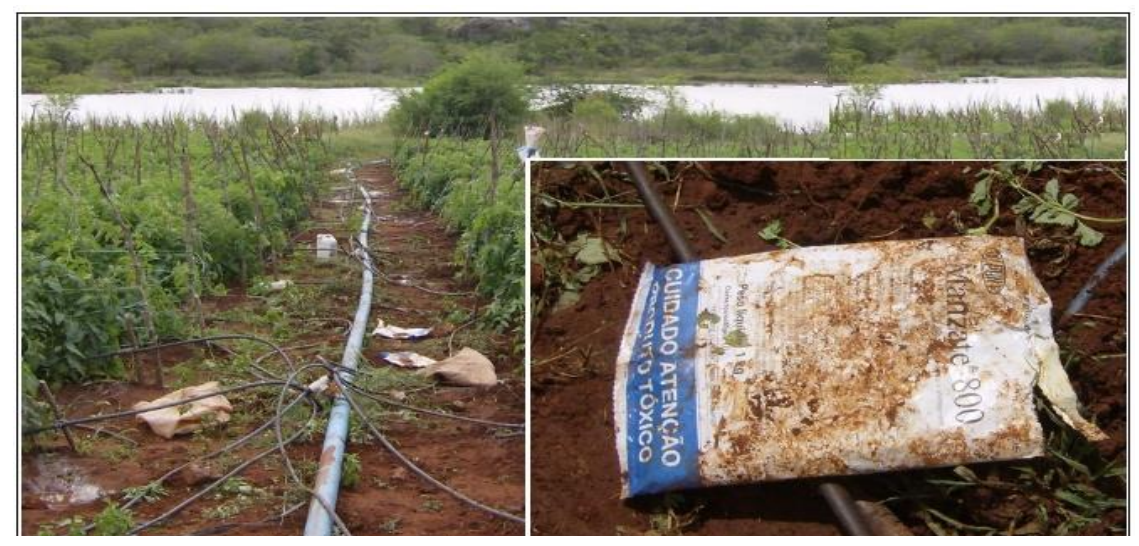

Figura 8: Aspecto da destinação dada às embalagens de agrotóxico em uma plantação de tomates localizadas as margens do rio Taperoá, no município de São João do Cariri - PB.

Uma vez concluído o levantamento dos dados, os valores encontrados nas diversas unidades de deterioração foram sumarizados na Tabela 3, assim como a ordem de prioridades mostrada por cada uma delas.

Tabela 3: Resumo da deterioração encontrada nas propriedades adjacentes ao rio Taperoá, no município de São João do Cariri, PB.

\begin{tabular}{|c|c|c|c|}
\hline \multicolumn{3}{|c|}{ Deterioração do Meio Ambiente } \\
\hline \multicolumn{3}{|c|}{ Socioeconômica } & Ambiental \\
\hline Social & Econômica & Tecnológica & \\
\hline Deterioração média & $68,33 \%$ & $67,31 \%$ & $18,96 \%$ \\
\hline
\end{tabular}




\begin{tabular}{|c|c|c|c|c|}
\hline \multicolumn{2}{|c|}{$44,95 \%$} & & 4 \\
\hline Prioridades & 3 & 1 & 2 & 4 \\
\hline \multicolumn{4}{|c|}{ Deterioração média, socioeconômica e ambiental = 49,89\% } \\
\hline
\end{tabular}

Conforme a Tabela 3, pode-se afirmar que as variáveis econômica e tecnológica foram as que mais contribuíram para o alto índice de deterioração $(49,98 \%)$ da atividade agrícola nas comunidades agrícolas do município de São João do Cariri. Assim, os diagnósticos socioeconômico e ambiental encontrados apresentaram, portanto, valores bem acima daquele tolerável, segundo o que registra a metodologia aplicada.

A última parte dos questionários reservou para os entrevistados um espaço para que os mesmos manifestassem suas maiores aspirações, no intuito de buscar a resolução dos problemas que dificultam a realização de suas tarefas cotidianas. Chamou à atenção, em especial, a falta de assistência técnica que figurou entre vinte e um por cento $(21 \%)$ dos participantes da pesquisa. Como segunda prioridade, a falta de mão de obra citada por pelo menos vinte por cento (20\%) dos proprietários. Esta escassez de oferta de força de trabalho se deve, como anteriormente citado, às políticas sociais (bolsas, aposentadorias e segurosafra) que desestimulam a oferta de trabalho alugado (como é localmente conhecida esta modalidade de ocupação). Outra prioridade que merece ser destacada é a falta de esgoto, reclamada por $26 \%$ dos proprietários. Já $15 \%$ reclamaram da falta de escolas na zona rural, seguido de um leque de prioridades menos reclamadas, mas não menos importantes.

\section{CONSIDERAÇÕES}

No espaço deste estudo, a sustentabilidade do setor agrícola se encontra num processo de comprometimento em praticamente todas as variáveis analisadas. Em decorrência das condições tecnológicas, de comercialização, de organização classista, do apoio institucional e ambiental locais, tem-se um quadro de deterioração, cujo valor é de cerca de $50 \%$, ou seja, com o comprometimento da metade de seu potencial.

O problema da contaminação do solo e da água, decorrentes dos processos produtivos na área foco deste estudo, carecem de uma reflexão mais aprofundada, haja vista a extrapolação desses impactos para áreas além daquelas da origem das ações. Um exemplo que aqui se quer demonstrar diz respeito à área em exame estar contida na bacia hidrográfica do Rio Taperoá que abastece o açude Epitácio Pessoa e é responsável pelo abastecimento do compartimento da Borborema, cuja população, cerca de seiscentos mil habitantes, fica exposta a esse tipo de contaminação.

Em suma, um meio para resolver as questões ambientais observadas nas práticas agrícolas mencionadas neste artigo, e que possibilite vislumbrar um cenário futuro mais otimista, são políticas públicas planejadas, sustentáveis e estáveis, bem como a observância da legislação ambiental. Soluções, enfim, que possibilitem a convivência do produtor em sua propriedade, renovação tecnológica na agricultura, possibilitando o aumento da produtividade e informação que permita a conscientização. Com tais ações, acredita-se ser possível produzir, conservar e mitigar os problemas que afetam o produtor. 


\section{REFERÊNCIAS:}

AB' SABER, A. N. Os domínios de natureza no Brasil: potencialidades paisagísticas. São Paulo: Ateliê Editorial, 2003.

ALTIERI, M. A. Linking ecologists and traditional farmers in the search for sustainable agriculture, Frontiers in Ecology and the Environment, [s.1.], v. 3, n. 1, 2004, p. 35-42.

ALVES, J. J. A. Geoecologia da Caatinga no Semiárido Brasileiro. Revista Climatologia e Estudo da Paisagem, Rio Claro, v. 2, n. 1, 2007, p. 58-71.

ANDRADE-LIMA, Diva M. de; SILVA, Marlene Maria da. Sertão Norte: área do sistema gado-algodão. Recife: SUDENE, 1982.

AZEVEDO, C. A. V. et al. Diagnóstico socioeconômico e ambiental de uma microbacia no município de Boqueirão - PB. Revista engenharia Ambiental, Espírito Santo do Pinhal, v. 2, n. 1, 2005, p. 100-114.

BARACUHY, J. G. V. Manejo integrado de microbacia no semiárido: estudo de um caso. Campina Grande: 2001. 221f. Tese (Doutorado). Universidade Federal da Paraíba.

BRASIL. Secretaria de Desenvolvimento Territorial SDT/MDA - Estudo Propositivo para Dinamização Econômica do Território do Cariri (Versão Preliminar). 2005.

CARVALHO, J. M.; EVANGELISTA, F. R.. Estudos de Sistemas Agroindustriais e de Turismo - algumas considerações sobre o êxodo rural no nordeste. Fortaleza: Banco do Nordeste do Brasil/ ETENE, 2001.

DANNI-OLIVEIRA, I. M.; MENDONÇA, F. Climatologia: noções básicas e climas do Brasil. São Paulo: Oficina de Texto, 2007.

DANTAS, José Robison Alcoforado; CAÚLA, José Antonio Lopes. Mapa Geológico da Paraíba: Texto Explicativo. Campina Grande: Grafset, 1982.

DINIZ, C. R. Aspectos sanitários de corpos lênticos temporários utilizados para consumo humano. Campina Grande: 1995. 143f. Dissertação (Mestrado), Universidade Federal da Paraíba.

FARIA, N. M. X.; FACCHINI, L. A.; FASSA, A. G.; TOMASI, E. Trabalho rural e intoxicações por agrotóxicos. Caderno Saúde Pública, Rio de Janeiro, v. 20, n. 5, p. 1298-1308, 2004

FRANCO, E. S. Avaliação do impacto ambiental causado pela exploração agropecuária em Boqueirão. Campina Grande, 2002. 88f. Dissertação (Mestrado). Universidade Federal de Campina Grande. 
INCRA, INSTITUTO BRASILEIRO DE COLONIZAÇÃO E REFORMA AGRÁRIA. Novo Retrato da Agricultura Familiar: O Brasil Redescoberto, Ministério do Desenvolvimento Agrário, Brasília, Fevereiro de 2000.

INSTITUTO BRASILEIRO DE GEOGRAFIA E ESTATÍSTICA. Censo populacional do Brasil. Rio de Janeiro. 2000.

Censo 2010. Disponível em: <http://www.ibge.gov.br/cidadesat/link.php?codmun=251400>. Acesso em 29 dez. 2011.

MELO, J. A. B. de. et al. Análise ambiental e do estado de deterioração da microbacia Riacho do Tronco, Boa Vista - PB. Revista Ambiente E Água, [s.1.], v. 5 n. 1, 2010. p. 172- 188.

MELO, M. L.; Bases geográficas dos problemas do Nordeste. Revista Brasileira de Geografia. [s.l.] v. 24, n. 4, 1962.

MINISTÉRIO DO DESENVOLVIMENTO SOCIAL, Folha de Pagamento - Bolsa Família por Município. Disponível em: http://www.mds.gov.br/bolsafamilia/Pagamento20Bolsa\%20Fam\%C3\%ADlia\%20\%20AGO\%202014.pdf. Acesso em outubro 2014.

PARAÍBA, Governo do Estado. Agência Executiva de Gestão das Águas (AESA). Dados meteorológicos dos municípios paraibanos. Disponível em: <http://www.aesa.pb.gov.br/perh/>. Acesso em jun. 2012.

PEREIRA, R. A. Impactos ambientais decorrentes das condições antroponaturais no Município de São João do Cariri-PB. Campina Grande, 2008. 106 f. Dissertação (Mestrado em Recursos Naturais), Universidade Federal de Campina Grande.

REBOUÇAS, A da C. Água na Região Nordeste: desperdício e escassez. Estudos Avançados, [s.n.], v. 11, n. 29, 1997, p. 127-154.

ROCHA, José Sales Mariano da. Manual de Projetos Ambientais. Santa Maria: Imprensa Universitária, 1997.

SCHNEIDER, S. Teoria social, agricultura familiar e pluriatividade. Revista Brasileira de Ciências Sociais - vol. 18 no. 51, 2003. p. 100-121.

TISDELL, C. A. Sustainable agriculture. IN: ATKINSON, G.; DIETZ, S.; NEUMAYER, E. Handbook of Sustainable Development. EE Publishng, Northampton, Massachusetts, 2007.

TUNDISI, J. G.; TUNDISI, T. M. Limnologia. São Paulo: Oficina de Textos, 2008. 